\title{
Peran Efikasi Diri (Self Efficacy) terhadap Kemampuan Pemecahan Masalah Matematika
}

\author{
Somawati Somawati
}

Universitas Indraprasta PGRI

ఏ e-mail: somadasay@gmail.com

\begin{abstract}
Mathematical problem solving ability is surely the must-have any students in doinga math problem that is abstract. But many of the students who have not been able to use the problemsolvingability in doing a math problem. Many of themassumed that mathematics is a difficult lesson, and it usually requires a high concentration oflearning math. So the efficacy of self (self efficacy) is in need of students to cope with these problems. Self-efficacy (self efficacy) refers to the belief that relates to the ability and willingness of a student to achieve and complete tasks and results of the study with the target time has been determined and self efficacy refers to the consideration of how big someone's beliefs about their ability to perform a number of learning activities and their ability to complete tasks. Students who have a good self-efficacy will be successful in theirlearning activities andcanperform academic duties smoothly likewise viceversa if the efficacy in low students then have students will quickly give up on any problems in dealing with. Hence the need for self-efficacy so that arise from the student is either the later will provide confidence in the ability of students in solving mathematical problems.
\end{abstract}

Keyword: self-efficacy, mathematical problem solving ability

Copyright (C) 2018 IICET (Indonesia) - All Rights Reserved

Indonesian Institute for Counseling, Education and Therapy (IICET)

\section{PENDAHULUAN}

Matematika merupakan ilmu universal yang mempunyai peran penting dalam berbagai disiplin ilmu dan mengembangkan daya pikir manusia (Syahbana, 2012). Matematika merupakan disiplin ilmu yang sangat bermanfaat dalam kehidupan sehari hari. Dengan belajar metematika seseorang dilatih untuk berpikir kreatif, kritis, jujur dan dapat mengaplikasikan ilmu matematika dalam menyelesaikan suatu permasalahan dalam kehidupan sehari-hari maupun dalam disiplin ilmu lainnya (Afrizon, Ratnawulan, \& Fauzi, 2012; Dewanti, 2011). Mengingat matematika merupakan ilmu yang sangat penting, maka hal ini lah yang menjadi salah satu faktor mengapa metematika dijadikan pelajaran wajib disetiap jenjang pendidikan, mulai dari sekolah dasar sampai perguruan tinggi.

Kurikulum untuk mata pelajaran matematika berubah seiring dengan perkembangan kurikulum yang berlaku. Permendiknas nomor 22 tahun 2006 menjelaskan bahwa salah satu tujuan pembelajaran matematika di sekolah adalah memecahkan masalah yang meliputi memahami masalah, merancang model matematika, menyelesaikan model, dan menafsirkan solusi. Kemampuan pemecahan masalah matematika merupakan bagian dari kurikulum matematika yang sangat penting karena dalam proses pembelajaran maupun penyelesaian, siswa dimungkinkan memperoleh pengalaman menggunakan pengetahuan serta keterampilan 
yang sudah dimiliki untuk diterapkan pada pemecahan masalah yang tidak rutin. Pemecahan masalah meliputi memahami masalah, merancang pemecahan masalah, menyelesaikan masalah, memeriksa hasil kembali (Siswono, 2005). Karena itu pemecahan masalah merupakan suatu tingkat aktivitas intelektual yang tinggi, serta siswa didorong dan diberi kesempatan seluas-luasnya untuk berinisiatif dan berfikir sistematis dalam menghadapi suatu masalah dengan menerapkan pengetahuan yang didapat sebelumnya.

Namun kemampuan pemecahan masalah yang siswa hadapi masih jauh dari harapan. Hasil studi Sumarmo (Ratnaningsih, 2003) berpendapat bahwa keterampilan menyelesaikan soal pemecahan masalah siswa sekolah menengah atas ataupun siswa sekolah menengah pertama masih rendah. Sejalan dengan hasil penelitian Fakhrudin (2010) terhadap Sekolah Menengah Pertama (SMP) secara umum hasil kemampuan tentang pemecahan masalah matematik siswa SMP belum memuaskan sekitar 30,67\% dari skor ideal.

Faktor-faktor yang menyebabkan timbulnya masalah-masalah dalam pembelajaran matematika antara lain masih banyaknya siswa beranggapan bahwa pelajaran matematika adalah pelajaran yang sukar dan biasanya belajar matematika memerlukan konsentrasi tinggi. Mereka menganggap matematika suatu pelajaran yang menakutkan, membosankan, dan menjadi beban bagi siswa karena bersifat abstrak, penuh dengan angka dan rumus. Selain itu, masih adanya sistem belajar yang menyamaratakan kemampuan siswa. Saat siswa belum menguasai materi dasar, sudah ditambah dengan materi lain. Para siswa pun cenderung tidak menyukai matematika karena dianggap sulit terutama dalam menyelesaikan soal-soal yang diberikan oleh guru matematika.

Menyikapi hal seperti ini diharapkan siswa mampu mengembangkan kemampuannya, agar pencapaian prestasi akademik yang optimal. Untuk itu, individu sebagai siswa selayaknya memiliki keyakinan dalam dirinya. Salah satu keyakinan diri seseorang mengenai kemampuan atau kecakapannya untuk melakukan tugas akademik adalah dengan efikasi diri. Menurut Bandura (Alwisol, 2009) efikasi diri akademik mengacu pada keyakinan yang berkaitan dengan kemampuan dan kesanggupan seorang pelajar untuk mencapai dan menyelesaikan tugas-tugas studi dengan target hasil dan waktu yang telah ditentukan. Efikasi diri akademik mengacu pada pertimbangan seberapa besar keyakinan seseorang tentang kemampuannya melakukan sejumlah aktivitas belajar dan kemampuannya menyelesaikan tugas-tugas belajar.

Park dan Kim (2006) menjelaskan efikasi diri akademik sangat penting bagi pelajar untuk mengontrol motivasi mencapai harapan-harapan akademik. Efikasi diri akademik jika disertai dengan tujuan-tujuan yang spesifik dan pemahaman mengenai prestasi akademik, maka akan menjadi penentu suksesnya perilaku akademik di masa yang akan datang. Namun efikasi diri yang dimiliki setiap siswa pasti berbeda, perbedaan ini di dasarkan pada tingkat keyakinan dan kemampuan setiap siswa. Siswa yang memiliki efikasi diri yang baik akan berhasil dalam kegiatan belajarnya dan dapat melakukan tugas-tugas akademiknya dengan lancar. Berbeda jika efikasi yang di miliki siswa rendah maka siswa akan cepat menyerah pada setiap permasalahan yang di hadapi.

Berdasarkan paparan di atas, maka penulis merasa perlu untuk meneliti dengan tujuan untuk menemukan secara empiris tentang pengaruh variabel efikasi diri (self efficacy) terhadap kemampuan pemecahan masalah matematika.

\section{METODOLOGI}

Subjek penelitian ini dilaksankan SMA Swasta Sekecamatan Jagakarsa sebanyak 60 peserta didik. Peneliti memperoleh data mengenai efikasi diri (self efficacy) menggunakan angket dan kemampuan pemecahan masalah menggunakan soal esai. Pengambilan sampel dalam penelitian ini menggunakan teknik gabungan antara proporsional dan random. Dalam menentukan jumlah anggota sampel dari setiap sekolah digunakan teknik proporsional, sedangkan untuk menentukan anggota sampel dari setiap sekolah dipilih secara acak.

Penelitian ini berlangsung selama enam bulan, yaitu dari Januari sampai dengan Juni 2017. Metode yang digunakan dalam penelitian ini adalah metode survei. Metode ini sering digunakan karena kemampuannya untuk memperkirakan suatu hasil yang mewakili suatu populasi apabila pengambilan sampel dilakukan dengan benar.

\section{HASIL DAN PEMBAHASAN}


Dari hasil sampel sebanyak 60 peserta didik, diperoleh nilai efikasi diri dan pemecahan masalah matematika. Secara deskriptif, hasil penelitian dapat digambarkan melalui tabel berikut:

\section{Tabel 1. Rangkuman data deskriptif}

Statistics

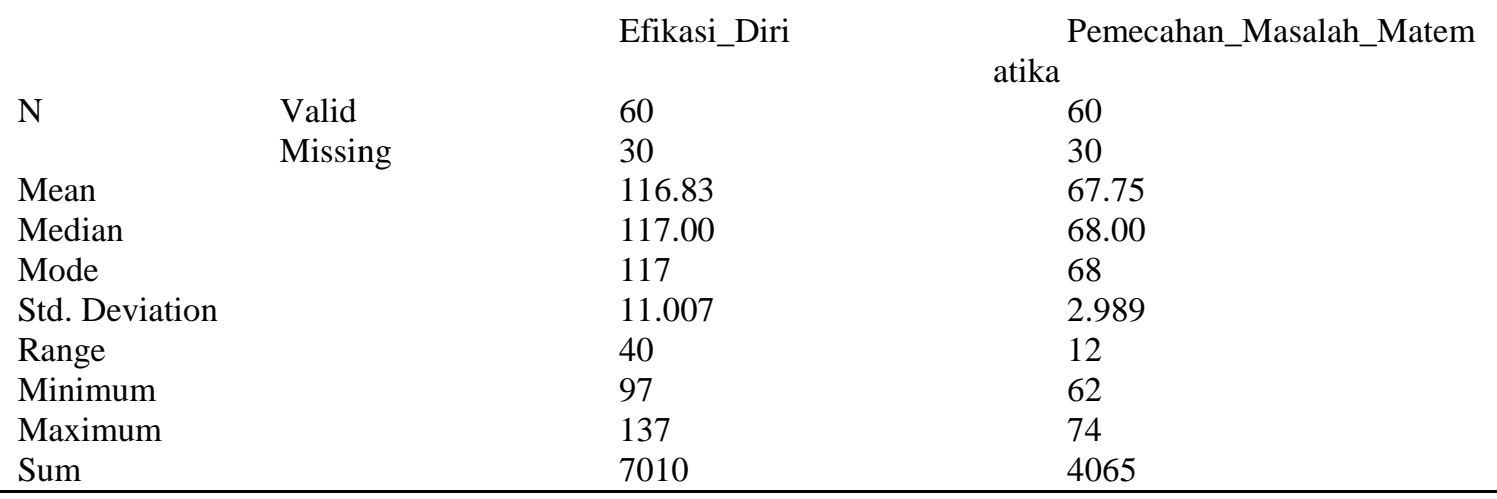

Kemudian, dalam menganalisis data dilakukan uji normalitas dan uji homogenitas. Untuk mengetahui apakah data berasal dari populasi yang berdistribusi normal atau tidak, maka dilakukan uji normalitas data dengan menggunakan SPSS 22.0. Untuk lebih jelasnya, hasil dari uji normalitas antara efikasi diri dan kemampuan pemecahan masalah matematika dapat dilihat pada tabel berikut:

Tabel 2. Rekapitulasi hasil perhitungan uji normalitas

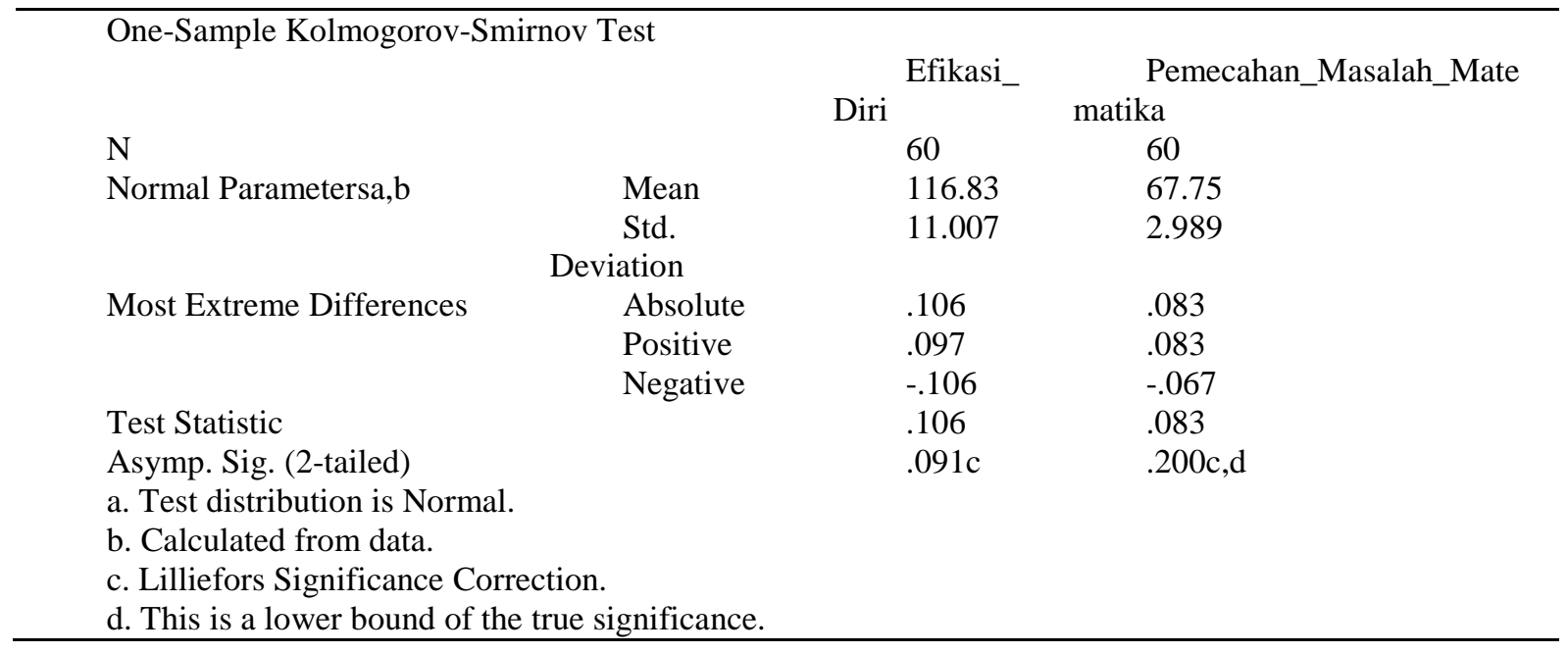

Diperoleh data nilai Kosmogorov-Smirnov Test $=0,106$ dengan probabilitas $0,91 \mathrm{c}$ (Asymp. Sig. (2tailed)). Persyaratan data berdistribusi normal jika nilai probabilitas atau p > 0,05 pada uji KosmogorovSmirnov. Oleh karena nilai $\mathrm{p}=0,91 \mathrm{c}$ atau $\mathrm{p}>0,05$ maka dapat disimpulkan bahwa data berdistribusi normal. Setelah kedua variabel pada penelitian ini dinyatakan berasal dari populasi yang berdistribusi normal, maka tahap selanjutnya yaitu dilakukan uji Linieritas Regresi yang dapat dilihat pada tabel berikut:

Tabel 3. Rekapitulasi hasil perhitungan uji linieritas regresi 


\begin{tabular}{|c|c|c|c|c|c|c|c|}
\hline \multicolumn{8}{|l|}{ ANOVA Table } \\
\hline & & & $\begin{array}{l}\text { Sum of } \\
\text { Square } \\
\text { S }\end{array}$ & $\begin{array}{l}\mathrm{D} \\
\mathrm{f}\end{array}$ & $\begin{array}{l}\text { Mean } \\
\text { Square }\end{array}$ & $\mathrm{F}$ & Sig \\
\hline \multirow[t]{5}{*}{$\begin{array}{l}\text { Pemecahan_Masalah_Matemat } \\
\text { ika * Efikasi_Diri }\end{array}$} & $\begin{array}{l}\text { Betwee } \\
\mathrm{n}\end{array}$ & $\begin{array}{l}\text { (Combine } \\
\text { d) }\end{array}$ & $\begin{array}{l}511.74 \\
0\end{array}$ & 8 & 63.968 & 210.345 & $\begin{array}{l}.00 \\
0\end{array}$ \\
\hline & Uroups & Linearity & $\begin{array}{l}509.00 \\
8\end{array}$ & 1 & $\begin{array}{l}509.00 \\
8\end{array}$ & $\begin{array}{l}1673.77 \\
1\end{array}$ & $\begin{array}{l}.00 \\
0\end{array}$ \\
\hline & & $\begin{array}{l}\text { Deviation } \\
\text { from } \\
\text { Linearity }\end{array}$ & 2.733 & 7 & .390 & 1.284 & $\begin{array}{l}.27 \\
7\end{array}$ \\
\hline & Within & ups & 15.510 & $\begin{array}{l}5 \\
1\end{array}$ & .304 & & \\
\hline & Total & & $\begin{array}{l}527.25 \\
0\end{array}$ & $\begin{array}{l}5 \\
9\end{array}$ & & & \\
\hline
\end{tabular}

Hasil pengujian persyaratan analisis data menunjukkan bahwa data berpola linier. Selanjutnya, pengujian hipotesis penelitian hasil perhitungan dengan menggunakan persamaan korelasi, signifikansi korelasi, dan signifikansi regresi. Ini dapat dilihat pada tabel 4.

Tabel 4. Koefisien korelasi

Coefficientsa

Model Correlations

le- $_{\text {order }^{\mathrm{Z}}}$ artial $^{\mathrm{P}}$ art

(Constant)

\begin{tabular}{lllll} 
ZDiri) & & & \\
Zscore(Efikasi & & & \\
\hline & 983 & 983 & 983
\end{tabular}

a. Dependent Variable: Zscore (Pemecahan_Masalah_Matematika)

Jadi, terdapat hubungan efikasi diri dan kemampuan pemecahan masalah matematika sebesar $(\mathrm{r}=$ 0,983) tergolong sangat tinggi. Pengaruh nilai efikasi diri terhadap kemampuan pemecahan masalah matematika sebesar $96,63 \%$ dan sisanya ditentukan oleh variabel lain.

Selanjutnya, signifikansi korelasi dapat dilihat dari tabel 5 di bawah ini. 
Tabel 5. Signifikansi korelasi

Coefficientsa

Model

$\begin{array}{llll}\text { Unstandardized } & \text { Standardized } & \text { T } & \text { Sig. } \\ \text { Coefficients } & \text { Coefficients } & & \end{array}$

B Std. Beta

Error

1 (Constant)

-
-024

.000

1.000

$9.336 \mathrm{E}-$

15

Zscore(Efikasi_Diri) $\quad .983$

$.024 \quad .983$

40.229

.000

a. Dependent Variable: Zscore(Pemecahan_Masalah_Matematika)

Pada tabel di atas diperoleh nilai t0 = 40,229 dan Sig. 0,000 < 0,05. Dengan demikian dapat dikalatan bahwa korelasi variabel $\mathrm{X}$ dengan $\mathrm{Y}$ atau pengaruh efikasi diri terhadap kemampuan pemecahan masalah matematika adalah signifikan. Kemudian regresi dimana dapat dilihat di tabel 6.

Tabel 6. Signifikansi regresi

\begin{tabular}{|c|c|c|c|c|c|c|}
\hline \multicolumn{7}{|c|}{ ANOVA $^{a}$} \\
\hline Model & & Sum of Squares & Df & Mean Square & $\mathrm{F}$ & Sig. \\
\hline \multirow[t]{3}{*}{1} & Regression & 56.959 & 1 & 56.959 & 1618.345 & $.000^{\mathrm{b}}$ \\
\hline & Residual & 2.041 & 58 & .035 & & \\
\hline & Total & 59.000 & 59 & & & \\
\hline \multicolumn{7}{|c|}{ a. Dependent Variable: Zscore(Pemecahan_Masalah_Matematika) } \\
\hline \multicolumn{7}{|c|}{ b. Predictors: (Constant), Zscore(Efikasi_Diri) } \\
\hline
\end{tabular}

Pada tabel Anova di atas, menunjukkan bahwa nilai $\mathrm{F} 0=1618,345$ dan Sig. $=0,000<0,05$. Hal ini menunjukkan bahwa H0 ditolak, dan dapat disimpulkan terdapat pengaruh yang signifikan efikasi diri (X) terhadap kemampuan pemecahan masalah matematika (Y). Jadi, terdapat pengaruh yang sangat besar antara efikasi diri dengan kemampuan pemecahan masalah matematika. Artinya hipotesis penelitian dapat diterima.

Setelah melakukan serangkaian penelitian, hasil yang telah peneliti dapatkan akan diuraikan sebagai berikut: Terdapat Pengaruh Efikasi Diri (X) terhadap Kempuan Pemecahan Masalah Matematika (Y), H0 ditolak, maka dapat disimpulkan bahwa terdapat terdapat pengaruh positif yang signifikan efikasi diri (X) terhadap kemampuan pemecahan masalah matematika (Y). Peserta didik akan mampu memecahkan masalah matematika apabila yakin akan kemampuan yang dia dapatkan di sekolah dan secara terus- menerus melakukan pengulangan akan meningkatkan efikasi diri peserta didik tersebut.

Dalam penelitian yang dilakukan Rezki Wahyu Hidayat dengan judul Pengaruh Efikasi Diri (Self Efikasi) Terhadap Kemampuan Pemecahan Masalah Matematika. Hasil penelitian menunjukan terdapat pengaruh yang signifikan antara efikasi diri (self efficacy) terhadap pemecahan masalah matematika. Hal ini berarti bahwa dalam menyelesaikan pemecahan masalah matematika, semakin tinggi efikasi peserta didik, 
semakin mudah menyelesaikannya. Pemecahan matematika dapat dilihat dari korelasi sebesar $\mathrm{r}=0,983$ yang tergolong sangat tinggi. Dari koefisien determinasi, pengaruh nilai efikasi diri terhadap kemamouan pemecahan masalah matematika sebesar $96,63 \%$ dan sisanya di tentukan variabel lain.

Sebagai bentuk kepercayaan diri untuk menjalankan tugas pada sebuah tingkatan pendidikan tertentu, efikasi diri akan membentuk sugesti dan persepsi atas keberhasilan dalam menyelesaikan tugas yang diberikan. Zimmerman menyimpulkan bahwa efikasi diri telah terbukti secara empiris memiliki peran penting sebagai pencetus motivasi belajar peserta didik. Tinggi rendahnya efikasi diri yang dimiliki oleh pelajar akan berpengaruh terhadap pilihan aktivitas yang dilakukan. Tingkat usaha yang dilakukan, tingkat kegigihan belajar dan tingkat reaksi emosional yang dikeluarkan. Kepercayaan atas kemampuan diri dalam menyelesaikan tugas atau aktivitas yang dibebankan akan mempengaruhi cara bertindak individu yang bersangkutan.

\section{SIMPULAN DAN SARAN}

Berdasarkan hasil penelitian yang diperoleh, dapat disimpulkan bahwa hasil penelitian menunjukkan terdapat pengaruh yang signifikan antara efikasi diri (self eficacy) terhadap pemecahan masalah matematika. Hal ini berarti bahwa dalam menyelesaikan pemecahan masalah matematika, semakin tinggi efikasi diri peserta didik, maka semakin mudah menyelesaikan masalah matematika. Pemecahan masalah matematika dapat dilihat dari korelasi sebesar $(\mathrm{r}=0,983)$ yang tergolong sangat tinggi. Dari koefisien determinasi, pengaruh nilai efikasi diri terhadap kemampuan pemecahan masalah matematika sebesar 96,63\% dan sisanya ditentukan oleh variabel lainnya.

Saran bagi peserta didik hendaknya percaya pada kemampuan diri sendiri saat mengerjakan soal-soal yang berkaitan dengan pemecahan masalah matematika. Jangan bergantung pada jawaban teman atau melakukan perbuatan buruk lainnya. Karena dengan percaya pada kemampuan diri sendiri, maka kita dapat mengukur sejauh mana kita memiliki kemampuan untuk menyelesaikan permasalahan pada pelajaran matematika dan dapat memotivasi diri untuk semakin lebih baik lagi.

Bagi guru para pendidik pada umumnya dan para guru matematika pada khususnya, untuk dapat memperhatikan kempuan pemecahan masalah matematika, sehingga guru bukan hanya sebagai guguan dan tiruan saja bagi siswanya tetapi tempat menggali kemampuan lain yang tidak dipelajari di sekolah secara langsung. Sehingga guru sendiri terpacu untuk menjadi lebih kreatif dalam menjalankan proses belajar diluar bidangnya sendiri. Bagi sekolah sekolah dapat menjadikan hasil penelitian ini sebagai bahan dalam upaya mengatasi hasil belajar matematika. Bagi peneliti peneliti dapat menambah pengetahuan sebagai pendidik dan sarana pengembangan kemampuan diri serta sebagai wadah melatih kecerdasan otak dalam menanggapi masalah khususnya masalah pendidikan.

\section{DAFTAR RUJUKAN}

Afrizon, R., Ratnawulan, R., \& Fauzi, A. (2012). Peningkatan Perilaku Berkarakter dan Keterampilan Berpikir Kritis Siswa Kelas IX MTsN Model Padang Pada Mata Pelajaran Ipa-fisika Menggunakan Model Problem Based Instruction. Jurnal Penelitian Pembelajaran Fisika, 1(1).

Alwisol. (2009). Psikologi Kepribadian. Malang: UMM Press

Dewanti, S. S. (2011). Mengembangkan kemampuan berpikir kritis mahasiswa Pendidikan Matematika sebagai calon pendidik karakter bangsa melalui pemecahan masalah.

Fakhrudin. (2010). Meningkatkan Kemampuan Pemecahan Masalah MatematikaSiswa Melalui Pembelajaran Dengan Pendekatan Open Ended. UPI: Bandung.

Kim, U \& Park Y. (2006). Factor InfluencingAcademic Achievement In Relational Cultures: The Role Of Self Relational, and Collective Efficacy. Jurnal Psikologi, Vol.21, No. 6.

N, Ratnaningsih. (2003). Mengembangkan Kemampuan Berpikir Matematik Siswa SMU Melalui Pembelajaran Berbasis Masalah. UPI: Bandung

Ruseffendi, E.T. (2005). Dasar-dasar Penelitian Pendidikan dan Bidang Non-Eksakta Lainnya. Bandung: PT. Tarsito.

Schunk, D.H. \& Pajares, F. (2001). The Development ofAcademic Self Efficacy.Faculty of Education, PurdueUniversity \& Emory University. 
Siswono, T. Y. E. (2005). Upaya meningkatkan kemampuan berpikir kreatif siswa melalui pengajuan masalah. Jurnal Pendidikan Matematika Dan Sains, 10(1), 1-9.

Sumarmo, U. Dedy. E dan Rahmat. (2005). Suatu Alternatif Pengajaran Untuk Meningkatkan Pemecahan Masalah Matematika Pada Guru Dan Siswa SMA.Laporan Hasil Penelitian FPMIPA IKIP Bandung.

Syahbana, A. (2012). Peningkatan kemampuan berpikir kritis matematis siswa smp melalui pendekatan contextual teaching and learning. EDUMATICA Journal Pendidikan Matematika, 2(1).

Taylor, S.E.Peplau, L.T. Sears, D.O. (2009). Psikologi Sosial, Edisi Kedua Belas. Jakarta: Kencana. 